University of Wollongong

Research Online

Faculty of Business - Papers (Archive)

Faculty of Business and Law

$1-1-2010$

Transaction costs and institutional trading in small-cap equity funds

Carole Comerton-Forde

University of Sydney

David R. Gallagher

University of Technology Sydney

Jumana Nahhas

University of Sydney

Terry S. Walter

University of Technology Sydney, twalter@uow.edu.au

Follow this and additional works at: https://ro.uow.edu.au/buspapers

Part of the Business Commons

Research Online is the open access institutional repository for the University of Wollongong. For further information contact the UOW Library: research-pubs@uow.edu.au 


\title{
Transaction costs and institutional trading in small-cap equity funds
}

\author{
Abstract \\ This paper examines the magnitude and determinants of trading costs for small-cap funds in Australia. \\ The total price impact for these funds is $0.99 \%(-0.34 \%)$ for purchases (sales). This is considerably larger \\ than costs reported in prior literature. Both purchases and sales exhibit price continuations after the trade \\ package, consistent with an information effect. Although we do not observe the directional asymmetry \\ typically shown in the literature, the magnitude of the total and permanent effects for purchases is larger \\ than for sales. We also show that price impact is related to fund inflows and outflows. \\ Disciplines \\ Business \\ Publication Details \\ Comerton-Forde, C., Gallagher, D. R., Nahhas, J. \& Walter, T. S. (2010). Transaction costs and institutional \\ trading in small-cap equity funds. Australian Journal of Management, 35 (3), 313-327.
}

This journal article is available at Research Online: https://ro.uow.edu.au/buspapers/1196 


\title{
Transaction costs and institutional trading in small-cap equity funds*
}

\author{
Carole Comerton-Forde ${ }^{\mathrm{a} \#}$, David R. Gallagher ${ }^{\mathrm{b}}$, Jumana Nahhas ${ }^{\mathrm{a}}$, Terry S. Walter ${ }^{\mathrm{b}}$ \\ ${ }^{a}$ Discipline of Finance, The University of Sydney \\ ${ }^{\mathrm{b}}$ School of Finance and Economics, University of Technology, Sydney
}

Current Draft: March 2010

\begin{abstract}
This paper examines the magnitude and determinants of trading costs for small-cap funds in Australia. The total price impact for these funds is $0.99(-0.34)$ percent for purchases (sales). This is considerably larger than costs reported in prior literature. Both purchases and sales exhibit price continuations after the trade package, consistent with an information effect. Although we do not observe the directional asymmetry typically shown in the literature, the magnitude of the total and permanent effects for purchases is larger than for sales. We also show that price impact is related to fund inflows and outflows.
\end{abstract}

JEL Classification: G14; G19

Keywords: transaction costs, small-cap funds, price impact

\footnotetext{
The authors acknowledge the investment managers who provided data to construct the Portfolio Analytics Database and the Securities Industry Research Centre of Asia-Pacific for providing ASX data. We thank Adrian Lee for excellent research support. We thank an anonymous referee, Tom Smith, Teddy Oetomo and seminar participants at the University of Queensland and the Australian National University for helpful comments and suggestions. We acknowledge funding provided by the Australian Research Council (DP0665826), the University of Sydney and the University of New South Wales.

\# Corresponding author: Carole Comerton-Forde ( $\underline{\text { carole.comerton-forde@ } @ \text { sydney.edu.au }}$ ).
} 


\title{
Transaction costs and institutional trading in small-cap equity funds
}

\begin{abstract}
This paper examines the magnitude and determinants of trading costs for small-cap funds in Australia. The total price impact for these funds is 0.99 (-0.34) percent for purchases (sales). This is considerably larger than costs reported in prior literature. Both purchases and sales exhibit price continuations after the trade package, consistent with an information effect. Although we do not observe the directional asymmetry typically shown in the literature, the magnitude of the total and permanent effects for purchases is larger than for sales. We also show that price impact is related to fund inflows and outflows.
\end{abstract}

JEL Classification: G14; G19

Keywords: transaction costs, small-cap funds, price impact 


\section{INTRODUCTION}

Researchers point to the cost of trading as an economically significant phenomenon that materially impacts portfolio decision-making and fund manager performance. ${ }^{1}$ The quantification of trading costs and analyses of their determinants has been the subject of ongoing research. Most empirical evidence on institutional trading costs has stemmed from studies assessing trading on major U.S. markets (Chan and Lakonishok $(1993,1995)$ and Keim and Madhavan $(1995,1997))$. These studies have typically measured trading costs by measuring the price impact of block trades. ${ }^{2}$ These studies show that price impact costs are significant and are influenced by trade size, firm capitalisation, and investment style. These studies have also consistently documented an asymmetry in both the magnitude and direction of trading costs incurred on purchases and sales. In general, (i) purchases are found to have higher price impact than sales and (ii) there is a price continuation after a purchase, consistent with an information effect, while there is a price reversal following a sale, consistent with a liquidity effect.

This paper extends the literature on institutional trading costs in three ways. First, it provides out-of-sample evidence in a non-U.S. market in a rapidly growing asset class, namely smallcap equities. Second, it offers a potential explanation for the observed asymmetry in posttrade effects in results documented in previous research. Third, we examine the effect of liquidity shocks on the trading costs of active small-cap fund managers.

\footnotetext{
${ }^{1}$ Examples include Keim (1999) and Wermers (2000).

${ }^{2}$ Bessembinder (2003) suggests that the ideal measure of trading costs is the "implementation shortfall" as defined by Perold (1988). This measure compares the value-weighted average price of a trade (including fees and commissions) to the price at the time an order decision was made. This measure requires proprietary data which is not generally available to researchers. Therefore, the institutional trading costs are often measured using price impact costs. We adopt this approach. More generally, the microstructure literature measures trading costs using effective and realised spreads. These measures are useful as proxies for costs incurred by small traders, rather than institutional trading costs, and therefore are not considered in this study.
} 
The paper examines trading costs in an Australian context. Since the cost of trading differs across markets, out-of-sample (non-U.S.) evidence represents an important contribution to the literature. Chiyachantana et al. (2004) and Domowitz et al. (2001) analyse costs across countries and find that trading costs vary across regions. Keim and Madhavan (1997) find that costs differ substantially across dealer versus order driven markets. The Australian Stock Exchange (ASX) is an electronic order driven market with no official market makers. Accordingly, it provides an interesting contrast to the dealer driven markets of the U.S. and a useful insight into order driven markets, which are now the most common market structure for equity markets around the world.

The paper considers the issue of trading costs in the context of small-cap equities. These stocks are less liquid than larger stocks, have lower analyst following, and are more sensitive to trading activity by institutional investors. Understanding transaction costs and transaction cost management in these stocks is particularly important. Analysis of small-cap funds is also of theoretical interest, since the cost of trading is as an important explanation of the observed small-firm effect (Aitken and Ferris, 1991). This sector is also of significance in Australia due to the recent exceptional performance of these funds. Chen et al. (2010) report that smallcap fund managers in Australia generate cumulative abnormal returns of approximately 0.60 percent per month for the period January 1998 to March 2004.

Over the sample period, small-cap funds in Australia have attracted significant inflows of new funds. Hence, these funds are less capital constrained than funds that have been typically examined in the trading cost literature. These funds are generally able to fund redemptions through new inflows rather than through stock sales. As a result, the sale of stock by these funds is less likely to be motivated by liquidity concerns. The literature argues that the 
asymmetry in the magnitude and direction of price impacts of purchases and sales is driven by the fact that purchases are information motivated whereas sales are liquidity motivated. We do not expect to observe a directional asymmetry in temporary price impacts (i.e., posttrade) for the small-cap funds because their selling activities are more likely to be based on information than a current lack of liquidity.

Employing a unique dataset, this paper evaluates the transaction costs incurred by 12 actively managed Australian small-cap equity funds offered to institutional investors, which are operated by nine unique institutions. ${ }^{3}$ This sample represents more than 55 percent of the Australian wholesale small-cap funds market based on value of funds under management. Consistent with expectations, the magnitude of trading costs incurred by these funds is significantly higher than the costs observed in previous research. The round-trip cost of a trade in a small-cap stock is shown to be 1.33 percent compared to only 0.27 percent reported by Aitken and Frino (1996) and 0.50 percent reported by Comerton-Forde et al. (2005) in earlier studies of trading costs for large stocks on ASX. ${ }^{4}$ There is significant asymmetry in the magnitude of the total price impacts observed for purchases and sales $(0.99$ percent for purchases verses -0.34 percent for sales). Both purchases and sales exhibit continuations in prices consistent with both having information content. Consistent with prior research, we find that trading costs are positively related to price and trade duration. Manager identity and the number of brokers involved in the execution also affect trading costs. The results also show that funds experiencing a positive flow exhibit higher post-trade information effects for sales than is the case for funds that sell on a negative flow. Thus if a fund sells a stock when

\footnotetext{
${ }^{3}$ These are the same funds (and data) used in the Chen et al. (2010) study.

${ }^{4}$ It is important to note differences in the samples used in this study compared to the previous Australian studies. This study examines trades from 12 small-cap funds, while Comerton-Forde et al. (2005) examined trades executed by a single large-cap fund manager. Aitken and Frino (1996) did not have access to data on fund managers' trades so developed a proxy using ASX SEATS data. The proxy used was the volume of trades executed by the same broker in a particular stock on a single day, provided that the total trading volume was greater than the stock's average daily trade volume.
} 
there is no liquidity-driven reason to do so, markets infer that the sale is information motivated, and react accordingly.

The remainder of this paper is organised as follows. Section 2 highlights the institutional details of the small-cap equity industry in Australia. Section 3 describes the dataset of smallcap equity transactions. Section 4 outlines the trade packaging methodology and the package statistics. Section 5 outlines the fund flow analysis and univariate statistics. Section 6 defines the price impact measures used and estimates the impact of the costs incurred by small-cap equity managers in the sample. Section 7 explores the determinants of price impacts and section 8 concludes.

\section{INSTITUTIONAL DETAILS}

\subsection{The Australian Equities Market}

The ASX is the $12^{\text {th }}$ largest market in the world with a total market capitalisation of approximately AUD 975 billion (as at June 2004). ${ }^{5}$ In June 2004 there were 1,459 companies listed on ASX. Standard and Poor's (S\&P) construct a range of benchmarks for the Australian equity market. The S\&P/ASX 100 Index comprises the largest 100 stocks that trade on the ASX. It accounts for approximately 75 percent of ASX market capitalisation. The Small Ordinaries (Small Ords) Index comprises stocks that are included in the S\&P/ASX 300 Index but not in the S\&P/ASX 100. This is the widely accepted definition of Australian small-cap stocks. The Small Ords Index represents approximately 7 percent of market capitalisation. The remaining stocks may be classified as Micro-caps. There is no index which covers the Micro-cap sector on ASX. Therefore, a Micro-cap proxy is developed. This

\footnotetext{
${ }^{5}$ The Australian pension fund market is fifth largest in the world (behind the United States, Japan, the United Kingdom and Canada). For 2009 statistics see http://www.austrade.gov.au/ArticleDocuments/2792/Data-Alert100205-Pension-Funds.pdf.aspx.
} 
Micro-cap proxy consists of those All Ordinaries Index stocks (the largest and most liquid 500 companies) that are not S\&P/ASX 300 stocks.

Table 1 reports average trading activity for the S\&P/ASX 100 Index, the Small Ords Index and Micro-cap stocks over the period January 2000 to July 2004. The results show that trading activity in Small Ords stocks is many times lower than trading activity in S\&P/ASX 100 stocks, but considerably higher than trading activity in Micro-cap stocks. For example, on average, S\&P/ASX 100 stocks trade 312 times per day, compared to only 42 and nine times per day for Small Ords and Micro-cap stocks, respectively. Similarly, on average, S\&P/ASX 100 stocks turnover is AUD 16.2 million per day, compared to AUD 0.55 million and AUD 0.095 million per day for Small Ords and Micro-cap stocks, respectively. Although Small Ords stocks are less liquid than S\&P/ASX 100 stocks, they are sufficiently liquid to allow institutional investors to invest in this segment of the market. These results demonstrate that although Small Ords stocks represent only a small proportion of the total market (by capitalisation), they provide reasonably liquid investment alternative to S\&P/ASX 100 stocks.

<Insert Table 1 here>

\subsection{The small-cap fund universe}

All small-cap equity funds in Australia are actively managed. Small-cap fund prospectuses indicate that their investment universe is defined as all stocks within the Small Ords Index. According to InvestorWeb a total of 32 funds comprise the small-cap wholesale funds management industry, and these are managed by 24 unique institutions. Based on ASSIRT ${ }^{6}$ figures, the total value of funds under management in small-cap equities is AUD 4,203

\footnotetext{
${ }^{6}$ ASSIRT is an Australian data provider that provides managed fund and ratings data for funds in Australia.
} 
million as at June $2004,^{7}$ where small-cap funds under management have grown more than five times since January $2000 .^{8}$

Management fees vary between small-cap equity funds, ranging from 0.53 percent to 1.65 percent per annum. Indeed, the average management expense ratio for small-cap funds, documented by Chen et al. (2010), was 8.4 basis points per month (i.e. $1.01 \%$ per year). Most institutional small-cap equity funds close to new money when they obtain AUD 500 million in funds under management, or approximately 1 percent of the value of the small-cap market (Fechner, 2004).

\section{DATA}

Data on the aggregate daily trades of 12 actively managed small-cap funds (operated by nine different managers) are obtained from the Portfolio Analytics Database. The total value of assets under management by the 12 funds is AUD 2,373 million at June 2004. Therefore, these funds account for over 55 percent of the small-cap equity fund's universe. Chen et al. (2010), who examine the same 12 funds, demonstrate that the returns-based performance of the funds in this sub-sample is consistent with the performance of the universe of small-cap funds. This demonstrates that this sample of managers is representative of the whole smallcap market.

The data comprising the Portfolio Analytics Database are collected directly from each fund manager. Data are provided on the basis that the identity and trading records of each institution remains confidential. We examine the period January 2000 to March 2004. During

\footnotetext{
${ }^{7}$ When retail small-cap funds are included, ASSIRT figures demonstrate that the total small-cap fund industry value, based on funds under management, is around AUD 6 billion.

${ }^{8}$ See Chen et al. (2010) for further details of the growth of small-cap funds in Australia.
} 
our sample period we have 46,830 observations, representing aggregated daily transactions for each fund manager. Of these, 26,577 are purchases and 20,253 are sales. Each observation contains several fields indicating the dates on which trades took place, the identity of the stock traded, the volume of the stock traded, the direction of trade, the volume-weighted average price (VWAP) of all trades by the specified manager in the specified stock on a particular day, and the identity of the broker executing the trade.

ASX SEATS stock price data are obtained from the Securities Industry Research Centre of the Asia-Pacific (SIRCA). These data contain detailed information about each stock in the Australian market, including daily opening and closing prices, the daily high and low prices, best bid and ask prices at the open and close and daily trading volumes and values. Relevant market data are extracted from this database and matched to the Portfolio Analytics Database for each stock traded by a fund manager.

\section{TRADE PACKAGE METHODOLOGY AND STATISTICS}

Institutional investors often break up their orders into multiple trades, spanning several (and not necessarily adjacent) days. This strategy is adopted in order to disguise their trade execution and avoid excessive market impact costs. Chan and Lakonishok (1995) develop a trade 'packaging' methodology, whereby individual trades in a stock are aggregated to the order level by combining trades that occur in a specific stock on adjacent days. They propose a five-day 'gap' definition. This means that all trades in one particular stock on consecutive days are taken to be part of the same package until no trades are executed in the stock for five consecutive days or more. This definition is applied to the dataset and results in 13,913 'trade 
package' observations. ${ }^{9,10}$

Table 2 reports descriptive statistics for the trade packages. Fifty five percent of packages across all stocks are purchases and forty five percent are sales. For both purchases and sales, the frequency of packages traded in Small Ords stocks is approximately 71 percent. Packages trading S\&P/ASX100 stocks account for approximately seven percent of the purchase transactions and ten percent of the sales. The remaining approximately 20 percent of packages are in Micro-cap stocks or in stocks which are recently listed and therefore not included in any of the S\&P indices.

All subsequent analysis in the paper focuses on trading in Small Ords stocks. Trading in other stocks may enhance portfolio returns and reduce transaction costs; however, we are interested in measuring the transaction costs of the stocks where the managers have a mandate to trade. Stocks are sorted into size quartiles, each year, based on average market capitalisation. A breakdown of the size classification by market capitalisation appears in Panel B of Table 2. The average size of stocks in the smallest quartile is AUD 92 million (AUD 87 million) for purchases (sales), and the average size of stocks in the largest quartile is AUD 714 million (AUD 738 million) for purchases (sales).

$<$ Insert Table 2 here>

\footnotetext{
${ }^{9}$ Not all of the fund manager's individual trades are packaged. About 15 percent of the trades are omitted due to managers reporting transactions prices that are either not within the high/low prices reported for the stock in a given day, or because there was no transaction in the stock on the day that the manager reported to have traded the stock.

${ }^{10}$ The sensitivity of the method to the length of the 'gap' used (e.g. five days, six days) is also analyzed in order to ensure the results are not contingent on the time period chosen. The package length does not influence the results and therefore only the five day 'gap' package results are reported.
} 
Inconsistent with prior research, there is only a weak association between package value and stock size. For example in Panel $\mathrm{C}$ of Table 2, the mean purchase package value for the smallest market capitalisation quartile is AUD 315,000, whilst the mean package value for the highest market capitalisation quartile is AUD 353,000. Similarly, for sales, the mean package value for the smallest market capitalisation quartile is AUD 309,000, whilst the mean package value for the highest market capitalisation quartile is AUD 377,000. There is somewhat greater variation in the median package value across the size quartiles, where purchase (sale) values are AUD 129,000 (AUD 115,000) for the first quartile and AUD 167,000 (AUD 182,000) for the fourth.

Panel D of Table 2 reports descriptive statistics by trade complexity. Trade complexity is proxied by the logarithmic ratio of the package trade volume to the average trading volume over the 40 days prior to the beginning of the package. There is an inverse relation between stock size and trade complexity. For packages in the smallest capitalisation stocks, this ratio is 2.44 for purchases and 3.32 for sales. This shows that fund managers are seeking to execute over twice the average daily trading volume of the stock for the smallest quartile. In contrast, packages in the highest capitalisation stocks typically execute 0.38 times (purchases) and 0.35 times (sales) the normal daily trading volume. The relative size of these packages can be compared to those reported in Chan and Lakonishok (1995), where the average values for the trade complexity proxy were approximately 0.66 and 0.61 for purchases and sales, respectively. For our sample, both buy and sell trades are 0.78 times average trading volume for all packages.

Panel $\mathrm{E}$ of Table 2 reports the average number of trading days taken to execute a trade package (i.e., duration) for Small Ords stocks. On average purchase (sale) packages are 
executed over 3.5 (3.7) days. The median package executes in one day. There is an inverse relation between stock size and duration. Packages in the smallest quartile of stocks take approximately 3.7 (5.4) days to execute for purchases (sales) compared to 3.1 (3.4) days for purchases (sales) in the largest quartile of stocks. This compares to Chan and Lakonishok (1995) where 59 (63) percent of purchases (sales) are executed in less than one day.

\section{FUND FLOW MEASURE}

Fund inflows and outflows have been found to affect the risk-adjusted returns of purchases and sales and this is attributed to the liquidity demands of funds. For example, Alexander et al. (2007) find funds experiencing heavy inflows tend to purchase poor performing stocks as they attempt to work off excess liquidity. As such, we investigate whether the price impact of trade purchases and sales are also similarly affected by such liquidity demands. For example, during days of heavy inflows, we expect fund purchases to face higher price impact due to the urgency in placing excess liquidity. In contrast, fund sales will experience lower price impact as funds have no urgency in selling during times of heavy inflow.

To capture the effect of fund flows, trade packages are classified into fund flow groups using a proxy method for flow activity. We develop a daily fund flow measure based on each fund's daily transactions, where for a given day, we net out all purchases and sales made by each fund. For each fund, we rank the days based on the percentage of net purchases or sales. And scale this by the previous month's fund net asset value. 'Inflow' days are those that are ranked in the top quartile of net buying days, and 'outflow' days are those that are ranked in the top quartile of net selling days. ${ }^{11}$ All remaining days are classified as 'no flow' days.

\footnotetext{
${ }^{11}$ The average fund daily flow percentage threshold, to be classified as positive or negative flows, is 1.14 and 0.93 percent respectively.
} 
Each trade package is classified as an inflow, outflow, or no flow package based on the fund flows on the day the first trade in the package begins. Table 3 reports descriptive statistics for the packages partitioned into flow groups. Panel A of Table 3 shows that there is little difference between the average size of stocks traded by flow groups. Similarly, Panel B of Table 3 reports that the average dollar value of the packages is generally similar for positive flow days and negative flow days. The average purchase (sale) package for positive flow days is AUD 335,000 (AUD 333,000) compared to AUD 322,000 (AUD 336,000) for negative flow days. Positive flow day purchases tend to be larger than negative flow day purchases when the package is scaled by normal trading volume. The average package size relative to normal daily volumes for positive flow days is $0.82(0.91)$ for purchases (sales) compared to $0.55(0.77)$ for negative flow days (Panel $\mathrm{C}$ of Table 3). Negative flow day purchases tend to be traded more patiently, with an average duration of 2.9 days compared to 2.1 for positive flow days. For sales, the average duration for negative flow days (2.4) is similar to those for positive flow days (2.6).

<Insert Table 3 here>

\section{PRICE IMPACT MEASURES}

The transaction cost literature has largely focussed on the price impact of block trades. Price impact measures seek to capture the deviation in transaction prices caused by the block trade (i.e. what would the price have been, in the absence of the trade?). Given that it is not possible to observe what the price would have been in the absence of the trade, there is no single unambiguous measure of price impact. As a result a range of benchmark prices are typically considered when estimating price impact. 
We measure price impacts using the approach set out by Holthausen et al. (1987) which are calculated using the following:

$$
\begin{aligned}
& P I_{\text {temporary }}=\ln \left(\frac{\text { price }}{\text { close }}\right) \\
& P I_{\text {permanent }}=\ln \left(\frac{\text { close }}{\text { open }}\right) \\
& P I_{\text {total }}=\ln \left(\frac{\text { price }}{\text { open }}\right)
\end{aligned}
$$

where $\mathrm{PI}_{\text {temporary }}, \mathrm{PI}_{\text {permanent }}$ and $\mathrm{PI}_{\text {total }}$ represent temporary, permanent and total measures of price impact, price is the volume weighted price of trades executed within the trade package, open is the opening price on the first day of the package and close is the closing price on the last day of the package. ${ }^{12}$ The total price impact represents the cost of getting set (i.e., the market impact costs). It is expected to be positive for purchase transactions (i.e., the trade price is above the opening price) and negative for sell trades (i.e., the selling price is below the opening price). If buy trades have information content then the closing price will be above the trade price, and the temporary effect is of negative sign. If buyers pay a liquidity premium, the closing price will be below the trade price, and hence the temporary effect will be of positive sign. For sell trades an information effect (i.e., prices continue to fall following the trade) will have a positive sign, while a liquidity effect will have a negative sign. By construction, the permanent effect is the sum of the total effect and the temporary effect multiplied by -1 . For our univariate analysis in Tables 4 and 5, we follow Chiyachantana et al. (2004) and adjust the price impact measures for market conditions using the Small Ordinaries Accumulation Index as the market return.

\footnotetext{
12 The opening and closing prices are also proxied using the mid-point of the best bid and ask price at the open and the close. The results are qualitatively consistent using these measures and therefore are not presented.
} 
Table 4 reports summary statistics for the three price impact measures used. Principal weighted measures of price impacts are reported as they provide a better indication of the economic cost of these trades to fund managers. For all trade packages (reported in the first row) total price impact for purchases (sales) is 0.99 percent $(-0.34$ percent), representing a round trip of 1.33 percent. Like previous research there is significant asymmetry between the magnitude of the price impact of purchases and sales. These costs are considerably higher than those reported for the Australian market in previous large-cap research. Aitken and Frino (1996) reported total price impact costs of 0.27 (0.00) for purchases (sales) while ComertonForde et al. (2005) reported costs of 0.34 percent for purchases and 0.16 percent sales ${ }^{13}$. Round trip costs are therefore 0.27 percent in Aitken and Frino (1996) and 0.50 percent in Comerton-Forde et al. (2005). We observe higher costs, as expected, because our sample relates to smaller stocks than those previously studied in the Australian literature.

\section{<Insert Table 4 here>}

Inconsistent with prior research, there is symmetry in the direction of the post-trade information effects. Both purchases and sales exhibit price continuations following the package. The temporary price impact for purchases is -0.21 percent compared to 0.06 percent for sales. Previous research by Alexander et al. (2007) has documented an asymmetry in the direction of price impacts for purchases and sales and has attributed this result to the fact that purchases are motivated by information, whereas sales may be motivated either by information or by liquidity needs. The symmetry in our results (i.e., both purchases and sales have an information effect) may also be explained by the fact that there have been substantial inflows of new capital into small-cap funds over the period examined. As a result, the funds are less capital constrained and are more able to fund redemptions from cash inflows; hence liquidity motivated sales are less likely to be required. Further, the large inflow of capital

\footnotetext{
${ }^{13}$ In Comerton-Forde et al. (2005) impact costs for sales are multiplied by -1 . Thus the value of 0.16 percent means that the trade price for a sale is below the opening price, consistent with a positive market impact cost.
} 
means that funds will invest on weaker information signals. Accordingly, the information component of purchases is expected to be lower than for funds which have smaller capital inflows.

To examine these issues further, the sample is partitioned into flow groups based on whether the trade package begins on a positive or negative flow day (as defined in Section 4). Sell trade packages starting on positive flow days face less capital constraints and hence are less likely to be liquidity motivated. In contrast, sell trade packages which begin on negative flow days will be more likely to be liquidity motivated. Our results, reported in Table 4, reinforce the capital constraint hypothesis for sales, with negative flow days having lower and statistically different total and temporary price impacts to positive flow days. ${ }^{14}$ In fact, positive flow day sales have total negative price impact of 0.90 percent and -0.58 percent for temporary price impact (with a permanent price impact of 1.49 percent, i.e., the stock rises during the package despite it being a sell trade). In contrast sell packages that start on negative flow days incur a market impact cost of -0.21 percent and a subsequent liquidity effect of - 0.04 percent. We do not find evidence supporting a capital constraint hypothesis for purchases, with negative and positive flow purchases experiencing statistically similar price impacts for total, temporary and permanent components.

\section{DETERMINANTS OF PRICE IMPACT}

The determinants of price impact are assessed by adopting and extending the regression framework that has frequently been used in the transaction cost literature since Chan and Lakonishok (1993). The following regression model is estimated:

$$
\begin{aligned}
& P I=\alpha+\beta_{1} \ln \text { Market }+\beta_{2} \ln \text { Mcap }+\beta_{3} \ln \text { TrComp }+\beta_{4} \text { Vol } \\
& +\beta_{5} \text { Duration }+\beta_{6} \ln \text { Fundsize }+\beta_{7} \text { NegFlow }+\beta_{8} \text { PosFlow }+\varepsilon_{i}
\end{aligned}
$$

\footnotetext{
${ }^{14}$ Results for positive and negative flow groups are comparable as they have similar duration as shown in Table 3.
} 
Where $P I$ refers to the either total price impact or permanent price impact (unadjusted for market returns), lnMarket is the Small Ordinaries Index log return from the opening level on the first day of the trade package to the closing level on the last day of the trade package. InMcap is the natural logarithm of market capitalisation of the stock. $\ln \operatorname{Tr}$ Comp is the natural logarithm of the ratio between the volume trading in the package over the average normal trading volume in the package 40 days before the package begins. Vol is the standard deviation of the natural logarithm of daily stock returns in the past 180 days. InDuration is the natural logarithm of the number of days it takes to complete a package. NegFlow is a dummy variable equal to 1 if the trade package starts on a negative flow day, and 0 otherwise. PosFlow is an analogous measure using positive flow days.

Table 5 reports price impacts based on a number of package characteristics including size and trade complexity. These results show that there is a clear (though not monotonic) relation between price impact and market capitalisation. Smaller stocks exhibit larger price impacts. The total price impact of a purchase for a stock in the smallest quartile is 1.37 compared to 0.72 for a stock in the largest quartile. This trend is greater for sales, where the total price impact for a stock in the smallest quartile is -1.32 percent compared to negative price impact for a stock in the largest quartile of 0.33 percent. Trade complexity also influences price impact. The least complex trades display lower price impact than the most complex trades. For example, the total price impact for the most complex quartile of purchases (sales) is 1.48 (-0.61) percent compared to only $0.13(0.00)$ percent for the least complex purchases.

$<$ Insert Table 5 here>

Trades that take more than one day to execute incur substantially higher costs than single day trades. For example the total cost is $-0.08(-0.12)$ percent for purchases (sales) that are 
executed over one day, while they are $1.45(-0.46)$ percent for packages executed over multiple days. These results are consistent with Chiyachantana et al. (2004) who find that the execution of trades over several days increases price impact.

A more formal analysis of the above issues is conducted using equation 4 . The results of this model are reported in Table 6. The regression model is estimated separately for both purchases and sales for the total price impact measure (Panel A) and the permanent price impact (Panel B) with controls for fund fixed effects and style fixed effects (i.e. GARP (growth at a reasonable price), Growth, Style Neutral and Value). We also report the Fstatistic 'Pos flow=Neg flow' for the null hypothesis that the positive flow coefficient equals the negative flow coefficient.

\section{<Insert Table 6 here>}

Table 6 reports our results. Overall the range of adjusted $\mathrm{R}^{2}$ from 9.99 to 18.50 percent reported is consistent with previous studies examining the determinants of price impact. ${ }^{15}$ Examining Table 6 Panel A, we find the market return is positively related to the price impact of purchases and sales consistent with the regression results in Chiyachantana et al. (2004). Also consistent is that package duration is statistically significant with higher price impacts for both purchases and sales. Inconsistent to prior research however is that the association between complexity of the trade and price impact; we find insignificant coefficients. Volatility is significantly positively for sales (though not for purchases), suggesting the price impact of sales increases with higher volatility stocks. Fund size is also statistically significant and negative for purchases suggesting the larger the fund, the lower the price impact of trades.

\footnotetext{
${ }^{15}$ Chiyachantana et al. (2004) typically find full model adjusted $\mathrm{R}^{2}$ of approximately $1 \%$ to $4 \%$. Chan and Lakonishok (1995) report adjusted $\mathrm{R}^{2}$ of approximately $2 \%$ to $7 \%$.
} 
The multivariate results are also consistent with our univariate flow results from Table 4. 'Pos flow $=$ Neg flow' is statistically significant at the one percent level for sales using regressions that control for both fund and style fixed effects, suggesting that negative flow day sales have higher price impact than positive flow day sales. This difference amounts to 49 basis points $(0.61-0.12)$ using fund fixed effects or 0.69 basis points $(0.60+0.09)$ using style fixed effects. We do not find a statistical difference in price impact between positive and negative flow days for purchases when we control for fund fixed effects, though when we control for style, purchases on negative flow days have greater price impact than purchases on positive flow days. We find consistent results in Table 6 Panel B where the dependent variable is permanent price impact, except that volatility is statistically significant and negatively related to purchases, suggesting purchases in higher volatility stocks have lower permanent price impact.

\section{CONCLUSION}

This paper makes several contributions to the literature on institutional trading costs. The research provides out-of-sample (non-U.S.) evidence on the costs of trading, whilst addressing an important and increasingly popular asset class i.e., small-cap equities. Employing a representative sample of actively managed small-cap equity funds that are available to wholesale investors, this paper analyses the trades of 12 small-cap equity funds over the period January 2000 to March 2004. The results indicate that trading costs are

substantial, with the average cost of a round-trip transaction being 1.33 percent on a principal-weighted basis. This result is economically significant, since the average cumulative abnormal return for small-cap funds is estimated to be 0.60 percent per month (Chen et al., 2010). 
Consistent with previous literature, price, trade duration, complexity and manager identity are found to be important determinants of transaction costs. Volatility also has a strong positive effect on the cost of sales. This is to be expected since lower priced small stocks are commonly associated with higher volatility of returns (Cheung and $\mathrm{Ng}, 1992$ ). Price impact costs are positively related to duration, with trade packages taking multiple days to execute incurring higher costs. The investment style of active small-cap equity managers also influences costs, with the more patient value style of managers incurring lower transaction costs than GARP and neutral style managers.

This paper also examines price impact with respect to fund flow experience. We find that on days when a fund has positive flows sales have higher information effects than days when the fund has negative flows. The sale of a stock when there is no liquidity-motivated reason to do so is more likely to convey information to the market, and the market interprets such sales accordingly. 


\section{REFERENCES}

Aitken, M. and G. Ferris 1991. A Note on the Effect of Controlling for Transaction Costs on the Small Firm Anomaly: Additional Australian Evidence, Journal of Banking and Finance, $15,1195-1202$.

Aitken, M. and A. Frino 1996. Execution Costs Associated with Institutional Trades on the Australian Stock Exchange, Pacific-Basin Finance Journal, 4, 45-58.

Alexander, G. J., G. Cici and S. Gibson 2007. Does Motivation Matter When Assessing Trade Performance? An Analysis of Mutual Funds, Review of Financial Studies, 15, 125-150.

Bessembinder, H., 2003, Issues in assessing trade execution costs, Journal of Financial Markets 6, 233-257.

Chan, L. and J. Lakonishok, 1993. Institutional Trades and Intraday Stock Price Behavior, Journal of Financial Economics, 33, 173-199.

Chan, L. and J. Lakonishok, 1995. The Behavior of Stock Prices Around Institutional Trades, Journal of Finance, 50, 1147-1174.

Chen, C., C. Comerton-Forde, D.R. Gallagher and T.S. Walter, 2010. Investment Manager Skill in Australian Small-Cap Equities, Australian Journal of Management, forthcoming.

Cheung, Y. and L. Ng, 1992. Stock Price Dynamics and Firm Size: An Empirical Investigation, Journal of Finance, 47(5), 1985-1997.

Chiyachantana, C, P. Jain, C. Jiang and R. Wood, 2004. International Evidence on Institutional Trading Behavior and Price Impact, Journal of Finance, 59(2), 869-898.

Comerton-Forde, C., C. Fernandez, A. Frino and T. Oetomo, 2005, How broker ability affects institutional trading costs, Accounting and Finance, 45(3), 351-374.

Domowitz, I., J. Glen, and A. Madhavan, 2001. Liquidity, Volatility, and Equity Trading Costs Across Countries and Over Time, International Finance, 4(2), 221-255.

Fechner, S., 2004. Keeping an Eye on Closed Small-cap Funds, Navigator Research, Australia.

Holthausen, R., R. Leftwich and D. Mayers, 1987, The effect of large block transactions on security prices: A cross-sectional analysis, Journal of Financial Economics, 19, 237-267.

Keim, D., 1999. An Analysis of Mutual Fund Design: The Case of Investing in Small-cap Stocks, Journal of Financial Economics, 51, 173-194.

Keim D. and A. Madhavan, 1995. The Anatomy of the Trading Process: Empirical Evidence on the Behavior of Institutional Traders, Journal of Financial Economics, 25, 75-98. 
Keim, D. and A. Madhavan, 1997. Transaction Costs and Investment Style: An InterExchange Analysis of Institutional Trades, Journal of Financial Economics, 46, 265-292.

Perold, A., 1988, The implementation shortfall, Journal of Portfolio Management 14, 4-9.

Wermers, R., 2000 Mutual Fund Performance: An Empirical Decomposition into Stock Picking Talent, Style, Transaction Costs and Expenses, Journal of Finance, 55(4), 16551695. 
Table 1: Average trading activity of S\&P/ASX 100 Index, Small Ords Index and Micro-cap stocks

Table 1 reports average trading activity for S\&P/ASX 100, Small Ords and micro-cap stocks. There is no index that captures the Micro-cap sector on the ASX; therefore this sector is proxied by the All Ordinaries stocks minus the S\&P/ASX 300 stocks. This results in the largest 200 micro-cap stocks being included in this category. The reported variables include the average daily value traded, the average daily trade volume, the average daily number of trades and the average daily off-market volume for a typical stock in each category. All results are reported over a four year period from January 2000 to July 2004.

\begin{tabular}{lcccc}
\hline & $\begin{array}{c}\text { Daily trading } \\
\text { value (\$) }\end{array}$ & $\begin{array}{c}\text { Daily trading } \\
\text { volume }\end{array}$ & $\begin{array}{c}\text { Daily number of } \\
\text { trades }\end{array}$ & $\begin{array}{c}\text { Off-market trade } \\
\text { volume }\end{array}$ \\
\hline S\&P/ASX 100 & $16,282,498$ & $2,380,758$ & 312 & 634,188 \\
Small Ords & 555,232 & 402,986 & 42 & 60,913 \\
Micro-cap proxy & 94,902 & 131,717 & 9 & 10,305 \\
\hline
\end{tabular}


Table 2: Descriptive statistics for trade packages

Trade packages are generated using a five day gap definition, which assumes that all adjacent trades in a stock by one manager are part of one large order until the stock is not traded by the manager for five consecutive days or more. Panel A reports the frequency of packages for buys and sells. Panels B to E report results only for Small Ords stocks. Panel B gives a breakdown of the size classification of the stocks traded in the packages for both buys and sells. The smallest stocks are denoted as 1 whilst the largest stocks are denoted as 4 . Panel C reports summary statistics for the dollar value of packages based on this size classification. Panel D reports trade complexity which is measured the logarithmic ratio of the package trade volume to the average trading volume over the 40 days prior to the beginning of the package. Panel E reports the average number of days taken to execute a package.

\begin{tabular}{|c|c|c|c|c|c|c|c|c|c|c|}
\hline \multicolumn{11}{|c|}{ Panel A: Frequency of packages } \\
\hline & & & \multicolumn{4}{|c|}{ Purchases } & \multicolumn{4}{|c|}{ Sales } \\
\hline All Stoc & & & \multicolumn{4}{|c|}{7666} & \multicolumn{4}{|c|}{6247} \\
\hline Small O & tocks & & \multicolumn{4}{|c|}{5414} & \multicolumn{4}{|c|}{4411} \\
\hline S\&P/AS & O Stoc & & \multicolumn{4}{|c|}{540} & \multicolumn{4}{|c|}{644} \\
\hline \multicolumn{11}{|c|}{ Package data for Small-Ordinaries stocks } \\
\hline & All & (Small) & & & (Large) & All & (Small) & & & (Large) \\
\hline & Buys & 1 & 2 & 3 & 4 & Sells & 1 & 2 & 3 & 4 \\
\hline $\mathbf{N}$ & 5414 & 283 & 887 & 1669 & 2575 & 4411 & 213 & 678 & 1352 & 2168 \\
\hline \multicolumn{11}{|c|}{ Panel B: Breakdown of Size Classification by Market Capitalisation (Millions) } \\
\hline Mean & 472 & 92 & 188 & 314 & 714 & 494 & 87 & 182 & 322 & 738 \\
\hline SD & 302 & 32 & 59 & 92 & 259 & 327 & 38 & 57 & 98 & 293 \\
\hline Median & 404 & 87 & 186 & 303 & 656 & 426 & 82 & 182 & 313 & 659 \\
\hline Q1 & 238 & 69 & 147 & 245 & 524 & 242 & 65 & 146 & 249 & 521 \\
\hline Q3 & 645 & 106 & 228 & 374 & 865 & 653 & 105 & 218 & 391 & 903 \\
\hline \multicolumn{11}{|c|}{ Panel C: Dollar Value of Packages (Thousands) } \\
\hline Mean & 342 & 315 & 359 & 319 & 353 & 351 & 309 & 323 & 332 & 377 \\
\hline SD & 588 & 512 & 622 & 521 & 624 & 587 & 532 & 610 & 582 & 587 \\
\hline Median & 157 & 129 & 173 & 140 & 167 & 161 & 115 & 128 & 150 & 182 \\
\hline Q1 & 63 & 39 & 65 & 56 & 69 & 67 & 33 & 42 & 60 & 84 \\
\hline Q3 & 365 & 381 & 411 & 333 & 363 & 378 & 310 & 329 & 353 & 409 \\
\hline \multicolumn{11}{|c|}{ Panel D: Trade Complexity } \\
\hline Mean & 0.78 & 2.44 & 1.47 & 0.76 & 0.38 & 0.78 & 3.32 & 1.33 & 0.79 & 0.35 \\
\hline SD & 2.21 & 4.81 & 3.64 & 1.71 & 0.79 & 3.06 & 10.70 & 3.63 & 1.96 & 0.66 \\
\hline Q1 & 0.22 & 0.79 & 0.48 & 0.24 & 0.15 & 0.20 & 0.61 & 0.38 & 0.25 & 0.15 \\
\hline Median & 0.08 & 0.23 & 0.18 & 0.08 & 0.06 & 0.07 & 0.16 & 0.10 & 0.08 & 0.06 \\
\hline Q3 & 0.64 & 2.36 & 1.31 & 0.72 & 0.34 & 0.58 & 2.21 & 1.12 & 0.70 & 0.36 \\
\hline \multicolumn{11}{|c|}{ Panel E: Duration (Trading Day) } \\
\hline Mean & 3.5 & 3.7 & 4.4 & 3.5 & 3.1 & 3.7 & 5.4 & 4.1 & 3.6 & 3.4 \\
\hline SD & 4.8 & 6.7 & 5.9 & 5.0 & 3.8 & 5.1 & 7.6 & 5.6 & 5.1 & 4.5 \\
\hline Q1 & 1.0 & 1.0 & 2.0 & 1.0 & 1.0 & 1.0 & 1.5 & 1.0 & 1.0 & 1.0 \\
\hline Median & 1.0 & 1.0 & 1.0 & 1.0 & 1.0 & 1.0 & 1.0 & 1.0 & 1.0 & 1.0 \\
\hline Q3 & 4.0 & 4.0 & 6.0 & 4.0 & 4.0 & 4.0 & 6.0 & 5.0 & 4.0 & 4.0 \\
\hline
\end{tabular}


Table 3: Descriptive statistics for trade packages for flow groups

Trade packages are generated using a five day gap definition, which assumes that all adjacent trades in a stock by one manager are part of one large order until the stock is not traded by the manager for five consecutive days or more. The table reports results only for Small Ords stocks partitioned into positive, no flow and negative flow groups. A package is defined as a positive (negative) flow package if the net flow on the first day of the package is in the top (bottom) quintile of all net daily flows for the fund. Panel A gives the size classification of the stocks traded in the packages for both buys and sells. Panel B reports summary statistics for the dollar value of packages based on this size classification. Panel $\mathrm{C}$ reports trade complexity which is measured the logarithmic ratio of the package trade volume to the average trading volume over the 40 days prior to the beginning of the package. Panel D reports the summary statistics for the number of days taken to execute a package.

\begin{tabular}{|c|c|c|c|c|c|c|}
\hline & \multicolumn{3}{|c|}{ Purchases } & \multicolumn{3}{|c|}{ Sales } \\
\hline & Neg Flow & No Flow & Pos Flow & Neg Flow & No Flow & Pos Flow \\
\hline $\mathbf{N}$ & 650 & 2,932 & 1,832 & 1,722 & 2,272 & 417 \\
\hline \multicolumn{7}{|c|}{ Panel A: Size Classification by Market Capitalisation (Millions) } \\
\hline Mean & 543 & 452 & 479 & 521 & 475 & 479 \\
\hline SD & 312 & 298 & 302 & 324 & 330 & 313 \\
\hline Q1 & 279 & 224 & 242 & 261 & 231 & 240 \\
\hline Median & 505 & 383 & 414 & 467 & 402 & 414 \\
\hline Q3 & 722 & 629 & 647 & 692 & 629 & 659 \\
\hline \multicolumn{7}{|c|}{ Panel B: Dollar Value of Packages (Thousands) } \\
\hline Mean & 322 & 349 & 335 & 336 & 366 & 333 \\
\hline SD & 472 & 570 & 650 & 605 & 580 & 551 \\
\hline Q1 & 94 & 58 & 61 & 69 & 62 & 71 \\
\hline Median & 194 & 160 & 138 & 162 & 167 & 141 \\
\hline Q3 & 346 & 391 & 348 & 333 & 420 & 336 \\
\hline \multicolumn{7}{|c|}{ Panel C: Trade Complexity } \\
\hline Mean & 0.55 & 0.81 & 0.82 & 0.77 & 0.77 & 0.91 \\
\hline SD & 1.55 & 2.39 & 2.08 & 3.45 & 2.55 & 3.86 \\
\hline Q1 & 0.10 & 0.08 & 0.08 & 0.07 & 0.08 & 0.07 \\
\hline Median & 0.21 & 0.23 & 0.19 & 0.18 & 0.22 & 0.20 \\
\hline Q3 & 0.44 & 0.71 & 0.65 & 0.50 & 0.62 & 0.57 \\
\hline \multicolumn{7}{|c|}{ Panel D: Duration (Trading Days) } \\
\hline Mean & 2.9 & 2.8 & 2.1 & 2.4 & 3.1 & 2.6 \\
\hline SD & 2.5 & 3.4 & 2.5 & 2.9 & 3.6 & 3.3 \\
\hline Q1 & 1 & 1 & 1 & 1 & 1 & 1 \\
\hline Median & 2 & 2 & 1 & 1 & 2 & 1 \\
\hline Q3 & 4 & 3 & 2 & 2 & 4 & 3 \\
\hline
\end{tabular}




\section{Table 4: Summary Statistics for Price Impact Measures}

Principal weighted means for three price impact measures are presented for both purchases and sales. A positive (negative) flow trade package is defined as whether on the first day of the trade package, net buying (selling) is in the top quintile of all net buying (selling) days for the fund. Total refers to total price impact and is the logarithmic return from the weighted average price of the package to the opening price on the first day of the package. Temp refers to temporary price impact and is the logarithmic return from the weighted average price of the package to the closing price on the last day of the package. Perm refers to permanent price impact and is the logarithmic return from the closing price on the last day of the package to the opening price on the first day of the package. The price impact measures are adjusted for market conditions following Chiyachantana et al. (2004) and using the Small Ordinaries Accumulation Index as the market return.

\begin{tabular}{lccccccc}
\hline & & \multicolumn{3}{c}{ Purchases } & \multicolumn{3}{c}{ Sales } \\
\hline \multicolumn{1}{c}{ Flow Group } & Stat & Total & Temp & Perm & Total & Temp & Perm \\
\hline All & Mean & 0.99 & -0.21 & 1.20 & -0.34 & 0.06 & -0.41 \\
Neg Flow & & 1.07 & -0.26 & 1.33 & -0.21 & -0.04 & -0.18 \\
No Flow & & 0.92 & -0.13 & 1.05 & -0.64 & 0.24 & -0.88 \\
Pos Flow & & 1.08 & -0.31 & 1.39 & 0.90 & -0.58 & 1.49 \\
Neg Flow - Pos Flow & Mean & -0.01 & 0.06 & -0.07 & -1.11 & 0.55 & -1.66 \\
& t-stat & -0.04 & 0.35 & -0.23 & -4.43 & 2.87 & -4.34 \\
& Prob. & 0.97 & 0.73 & 0.82 & 0.00 & 0.00 & 0.00 \\
\hline
\end{tabular}




\section{Table 5: Package Characteristics and the Cost of Trading}

Principal-weighted mean price impacts are reported for both purchases and sales. A positive figure denotes a cost, whilst a negative denotes a benefit. Total refers to total price impact and is the logarithmic return from the weighted average price of the package to the opening price on the first day of the package. Temp refers to temporary price impact and is the logarithmic return from the weighted average price of the package to the closing price on the last day of the package. Perm refers to permanent price impact and is the logarithmic return from the closing price on the last day of the package to the opening price on the first day of the package. The price impact measures are adjusted for market conditions following Chiyachantana et al. (2004) and using the Small Ordinaries Accumulation Index as the market return. Costs are reported based on the market capitalisation classification of the stock underlying the package. The smallest stocks are denoted as 1 whilst the largest stocks are denoted as 4 . Costs are reported based on the trade complexity of the package defined as the logarithmic ratio of the package trade volume to the average trading volume 40 days prior to the beginning of the package. Costs are reported based on package duration, whether the package was executed over a single day or over several days.

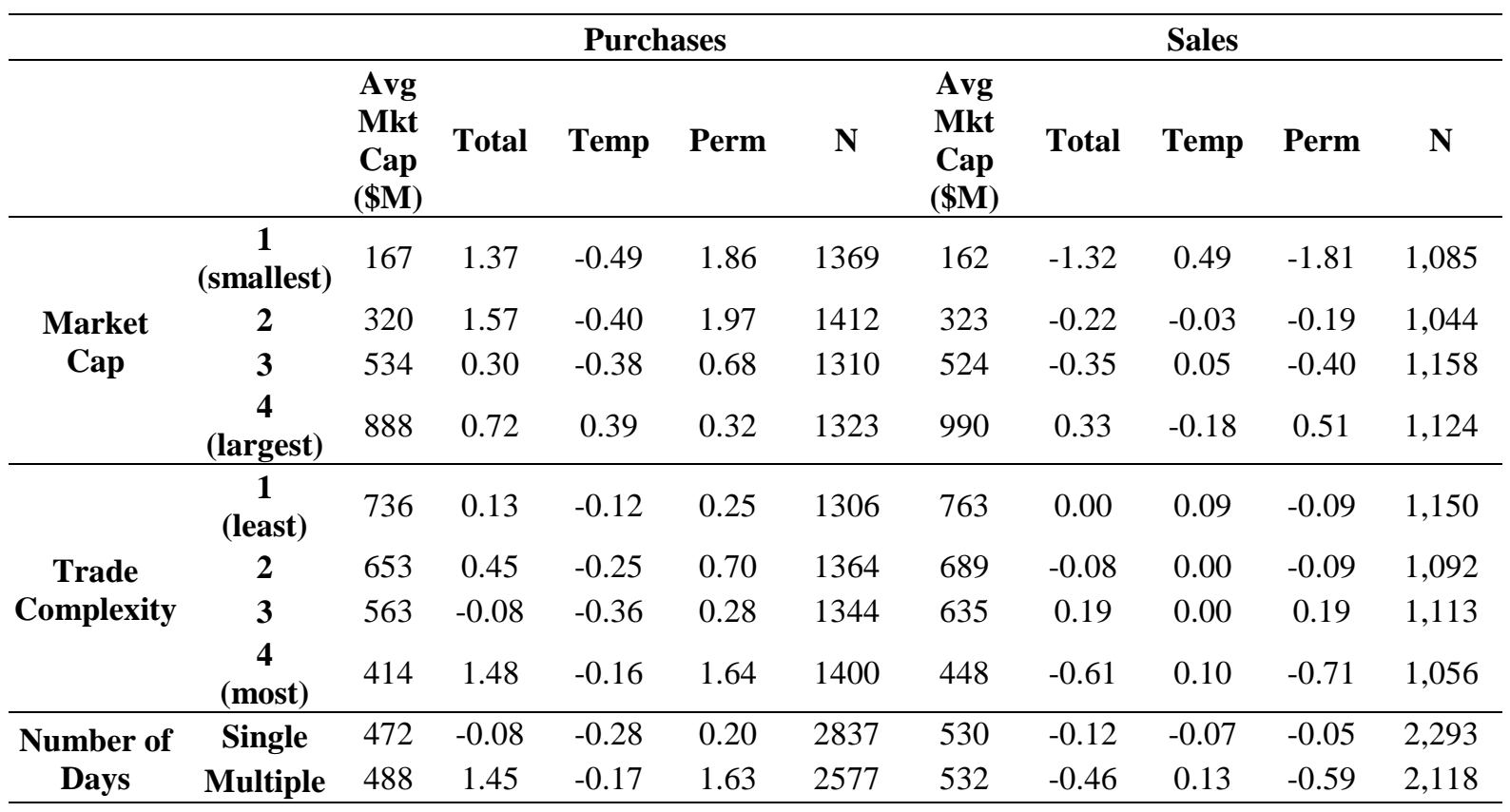


Table 6: The Determinants of Price Impact

Table reports the regression results for the following model:

$P I=\alpha+\beta_{1} \ln$ Market $+\beta_{2} \ln$ Mcap $+\beta_{3} \ln$ TrComp $+\beta_{4}$ Vol $+\beta_{5}$ Duration $+\beta_{6} \ln$ Fundsize $+\beta_{7}$ NegFlow $+\beta_{8}$ PosFlow $+\varepsilon_{i}$

Where PI refers to the total price impact in Panel A and permanent price impact in Panel B, lnMarket is the Small Ordinaries Index log return from the opening level on the first day of the trade package to the closing level on the last day of the trade package. InMcap is the natural logarithm of market capitalisation of the stock average package price. $\ln \operatorname{Tr} C o m p$ is the natural logarithm of the ratio between the volume trading in the package over the average normal trading volume in the package forty days before the package begins. Vol is the standard deviation of the natural logarithm of daily stock returns in the past 180 days. InDuration is the natural logarithm of the number of days it takes to complete a package. NegFlow is a dummy equal 1 if the trade package starts on a negative flow day, 0 otherwise. PosFlow is an analogous measure using positive flow days. 'Pos flow=Neg flow' is a F-test The reported $F$-stat statistics and the significance levels are based on running the regression with robust standard errors to account for heteroskedasticity.

\begin{tabular}{|c|c|c|c|c|}
\hline \multirow[b]{2}{*}{ Variable } & \multicolumn{4}{|c|}{ Panel A. Dependent Variable - Total Price Impact } \\
\hline & Purchases & Sales & Purchases & Sales \\
\hline Intercept & $4.16^{*}$ & $-10.14 * * *$ & 1.33 & $-7.07 * *$ \\
\hline Market Conditions & $0.49 * * *$ & $0.59 * * *$ & $0.51 * * *$ & $0.59 * * *$ \\
\hline In Mcap & 0.10 & $0.50 * * *$ & 0.13 & $0.35 * * *$ \\
\hline In Trcomp & 0.05 & 0.02 & $-0.07 *$ & -0.02 \\
\hline Vol & -0.06 & $-0.64 * * *$ & -0.07 & $-0.67 * * *$ \\
\hline In Duration & $0.46^{* * *}$ & $-0.54 * * *$ & $0.37 * * *$ & $-0.55 * * *$ \\
\hline In Fundsize & $-0.31 * * *$ & 0.06 & $-0.24 * * *$ & 0.09 \\
\hline Neg flow & 0.13 & 0.12 & $0.44 * * *$ & -0.09 \\
\hline Pos flow & 0.00 & $0.61 * * *$ & 0.12 & $0.60 * * *$ \\
\hline Pos flow=Neg flow & 1.01 & $6.43 * *$ & $6.39 * *$ & $12.55 * * *$ \\
\hline F Statistic & $49.42 * * *$ & $32.84 * * *$ & $62.99 * * *$ & $45.5^{* * *}$ \\
\hline Adjusted R-squared & 13.86 & 11.50 & 11.18 & 9.99 \\
\hline $\mathbf{N}$ & 5,414 & 4,411 & 5,414 & 4,411 \\
\hline \multirow[t]{2}{*}{ Fixed Effects } & Fund & Fund & Style & Style \\
\hline & \multicolumn{4}{|c|}{ Panel B. Dependent Variable - Permanent Price Impact } \\
\hline Variable & Purchases & Sales & Purchases & Sales \\
\hline Intercept & 3.24 & $-8.38 * *$ & $11.67 * * *$ & $-9.87^{*}$ \\
\hline Market Conditions & $1.10 * * *$ & $1.17 * * *$ & $1.09 * * *$ & $1.16 * * *$ \\
\hline In Mcap & 0.01 & $0.60 * * *$ & 0.00 & $0.80 * * *$ \\
\hline In Trcomp & -0.08 & 0.04 & 0.06 & 0.11 \\
\hline Vol & $-0.23 * *$ & $-1.21 * * *$ & $-0.21 * *$ & $-1.17 * * *$ \\
\hline In Duration & $0.54 * * *$ & $-0.92 * * *$ & $0.57 * * *$ & $-0.89 * * *$ \\
\hline In Fundsize & $-0.19 * * *$ & -0.05 & $-0.59 * * *$ & -0.22 \\
\hline Neg flow & $0.34 *$ & -0.13 & 0.11 & 0.11 \\
\hline Pos flow & 0.12 & $0.88 * * *$ & -0.01 & $0.86^{* * *}$ \\
\hline Pos flow=Neg flow & 1.48 & $12.91 * * *$ & 0.43 & $7.13 * * *$ \\
\hline F Statistic & $104.05 * * *$ & $67.88 * * *$ & $69.27 * * *$ & $45.79 * * *$ \\
\hline Adjusted R-squared & 17.31 & 14.29 & 18.50 & 15.45 \\
\hline $\mathbf{N}$ & 5,414 & 4,411 & 5,414 & 4,411 \\
\hline Fixed Effects & Fund & Fund & Style & Style \\
\hline
\end{tabular}

